\section{Molecular subtypes and imaging phenotypes of breast cancer}

\author{
Nariya Cho ${ }^{1,2,3}$ \\ ${ }^{1}$ Department of Radiology, Seoul National University Hospital, Seoul; 'Department of \\ Radiology, Seoul National University College of Medicine, Seoul; ${ }^{3}$ Institute of Radiation \\ Medicine, Seoul National University Medical Research Center, Seoul, Korea
}

During the last 15 years, traditional breast cancer classifications based on histopathology have been reorganized into the luminal A, luminal B, human epidermal growth factor receptor 2 (HER2), and basal-like subtypes based on gene expression profiling. Each molecular subtype has shown varying risk for progression, response to treatment, and survival outcomes. Research linking the imaging phenotype with the molecular subtype has revealed that non-calcified, relatively circumscribed masses with posterior acoustic enhancement are common in the basallike subtype, spiculated masses with a poorly circumscribed margin and posterior acoustic shadowing in the luminal subtype, and pleomorphic calcifications in the HER2-enriched subtype. Understanding the clinical implications of the molecular subtypes and imaging phenotypes could help radiologists guide precision medicine, tailoring medical treatment to patients and their tumor characteristics.

Keywords: Breast neoplasms; Gene expression profiling; Ultrasonography; Diagnosis

\section{Introduction}

Tumor size, lymph node status, histologic type, histologic grade, and estrogen receptor (ER), or progesterone receptor (PR), or human epidermal growth factor receptor 2 (HER2) expression status by immunohistochemistry (IHC) have been well established as prognostic and predictive factors for breast cancers. Yet the traditional classifications do not fully reflect the heterogeneity of breast cancer. For example, although women with ER-negative or HER2-negative tumors do not respond to endocrine or HER2-targeted therapy, respectively, women with ER-positive or HER2-positive tumors tend to show varying responses to each targeted treatment [1]. Thus, there has long been investigation into better classifications to predict outcomes for breast cancer patients.

During the last 15 years, a reshuffling of breast cancer classifications has been underway, from the histopathologic type to the molecular subtype determined by microarray-based gene expression profiling. Today, we recognize that ER-positive breast cancers and ER-negative breast cancers constitute different diseases [1]. In addition, the existence of the four intrinsic subtypes of "luminal A," "luminal B," "HER2-enriched," and "basal-like" has been demonstrated by extensive profiling at the DNA, microRNA, and protein levels by The Cancer Genome Atlas (TCGA) Network [2]. The intrinsic subtype is similar to the subtype based on mRNA gene expression profiling alone [3].

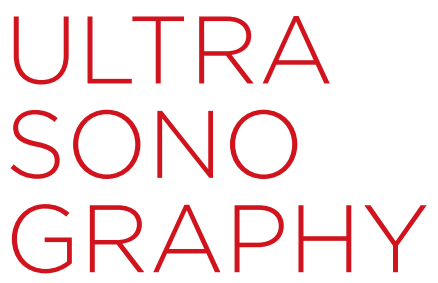

REVIEW ARTICLE

http://dx.doi.org/10.14366/usg. 16030 pISSN: 2288-5919 • elSSN: 2288-5943

Ultrasonography 2016;35:281-288

Received: June 23, 2016

Revised: July 19, 2016

Accepted: July 21, 2016

Correspondence to:

Nariya Cho, MD, Department of Radiology, Seoul National University College of Medicine, 103 Daehak-ro, Jongno-gu, Seoul 03080, Korea

Tel. +82-2-2072-1862

Fax. $+82-2-743-6385$

E-mail: river7774@gmail.com

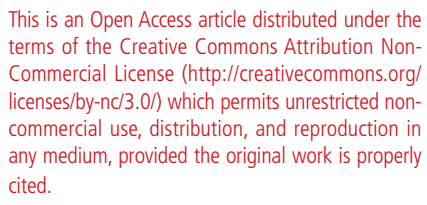

This is an Open Access article distributed under the terms of the Creative Commons Attribution NonCommercial License (http://creativecommons.org/ licenses/by-nc/3.0/) which permits unrestricted noncommercial use, distribution, and reproduction in any medium, provided the original work is properly cited.

Copyright (C) 2016 Korean Society of Ultrasound in Medicine (KSUM)

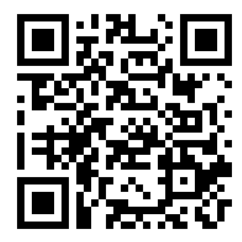

How to cite this article:

Cho N. The molecular subtypes and imaging phenotypes of breast cancer. Ultrasonography. 2016 Oct;35(4):281-288. 
Each subtype has shown different incidence, prognosis, response to treatment, preferential metastatic organs, and recurrence or disease-free survival outcomes $[3,4]$. Since 2011, the St. Gallen International Expert Consensus panel has used the subtype-based recommendation for systemic therapies for breast cancer. As full genetic analysis of breast cancer is not easily available in clinical practice due to its high cost and the extensive resources required, surrogate definitions of the subtype based on semiquantitative IHC scoring of ER, PR, and in situ hybridization tests for HER2 overexpression have been proposed (Table 1) [5]. The most recent 2015 St. Gallen International Expert Consensus has suggested that discrimination between patients who will or will not benefit from particular therapies is the key question (Table 2) [6].

In this article, the clinical implications of breast cancer subtypes and the imaging phenotypes of each subtype are reviewed to help radiologists understand breast cancer biology and identify their roles in translational research.

\section{Basal-like Subtype}

Analysis based on TCGA has confirmed that the basal-like subtype is a unique subtype among breast cancers. Basal-like tumors have the worst prognosis, while luminal A tumors have the best. Possible explanations for the differentiation include distinct cell-of-origin (e.g., cancer stem cells) and tumor subtype-specific genetic and epigenetic events for each tumor subtype [7]. As the majority (86\%) of triple negative breast cancers (TNBC) - those that show as ERnegative, PR-negative, and HER2-negative-correspond to the basal-like subtype [8], the terms TNBC and basal-like have been used interchangeably to refer to a tumor subtype. However, within the set of TNBC tumors, which make up 10\%-20\% of all breast cancers, all the intrinsic subtypes exist [9]. There are six molecular subtypes of TNBC, as follows: two basal-like (BL1 and BL2) subtypes, an immunomodulatory (IM) subtype, a mesenchymal (M) subtype, a mesenchymal stem-like subtype, and a luminal androgen receptor subtype [10]. The M group shows the worst outcomes and the IM group shows the best outcomes [8]. Rates of pathologic complete response $(p C R)$ following anthracycline/taxane chemotherapy are $25 \%-35 \%$, and patients achieving $p C R$ have better outcomes from among those patients with TNBC [11]. The distinction between basal-like and non-basal-like subtypes within TNBC is important for the choice of chemotherapy, in that carboplatin is as effective as docetaxel in basal-like subtypes, but less so in other intrinsic subtypes in the metastatic setting [6].

Tumor infiltrating lymphocytes are most often found in TNBC or HER2-positive cancers, and other highly proliferative breast cancers are associated with increased $p C R$, longer disease-free survival, and improved overall survival outcomes [6]. It has also been suggested that genes involved in immune, inflammatory, and/or chemokine pathways might be related to the prognosis of hormone receptor (HR)-negative tumors, and that proliferation-associated genes are related to the prognosis of HR-positive tumors [1].

\section{Luminal Subtype}

Approximately $70 \%$ of breast cancers are HR-positive breast cancers, and they show a more favorable prognosis than HRnegative breast cancers. Within HR-positive/HER2-negative breast cancer, $90 \%-95 \%$ of tumors are luminal A and B subtypes [8]. Compared to luminal A tumors, the luminal B subtype tends to show higher expression of proliferation genes [3] and worse baseline distant recurrence-free survival at 5 years and 10 years, regardless

Table 1. Surrogate definitions of intrinsic subtypes of breast cancer classification from the St. Gallen Consensus 2013

\begin{tabular}{|c|c|c|c|c|c|c|c|}
\hline \multirow{2}{*}{ Intrinsic subtype } & \multicolumn{6}{|c|}{ Clinicopathologic surrogate definition } & \multirow{2}{*}{ Type of therapy } \\
\hline & & ER & PR & HER2 & Ki-67 & Recurrence risk ${ }^{\mathrm{a})}$ & \\
\hline Luminal A & Luminal A-like & + & $+{ }^{\text {b) }}$ & - & Low $<14 \%$ & Low (if available) & $\begin{array}{l}\text { Endocrine therapy is often used alone } \\
\text { Cytotoxic therapy may be added }\end{array}$ \\
\hline \multirow[t]{2}{*}{ Luminal B } & $\begin{array}{l}\text { Luminal B-like } \\
\text { (HER2-negative) }\end{array}$ & + & - or low & - & High & High (if available) & $\begin{array}{l}\text { Endocrine therapy for all patients, } \\
\text { cytotoxic therapy for most }\end{array}$ \\
\hline & $\begin{array}{l}\text { Luminal B-like } \\
\text { (HER2-positive) }\end{array}$ & + & Any & $\begin{array}{l}\text { Over-expressed } \\
\text { or amplified }\end{array}$ & Any & NA & $\begin{array}{l}\text { Cytotoxics+anti-HER2+endocrine } \\
\text { therapy }\end{array}$ \\
\hline $\begin{array}{l}\text { ErbB-2 } \\
\text { overexpression }\end{array}$ & $\begin{array}{l}\text { HER2-positive } \\
\text { (non-luminal) }\end{array}$ & Absent & Absent & $\begin{array}{l}\text { Over-expressed } \\
\text { or amplified }\end{array}$ & NA & NA & Cytotoxics+anti-HER2 \\
\hline Basal-like & $\begin{array}{l}\text { Triple negative } \\
\text { (ductal) }\end{array}$ & - & - & - & NA & NA & Cytotoxics \\
\hline
\end{tabular}

Modified from Goldhirsch A et al. Ann Oncol 2013;24:2206-2223 [5], according to the Creative Commons license.

$E R$, estrogen receptor; PR, progesterone receptor; HER2, human epidermal growth factor receptor 2; NA, not applicable.

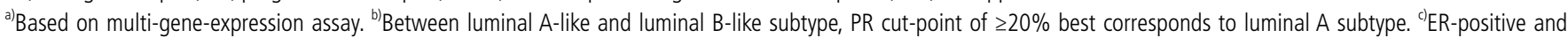
HER2-negative and at least one of: Ki-67 high, PR-negative or low, or recurrence risk high. 
of adjuvant systemic therapy, although luminal B tumors do show a higher $p C R$ rate following neoadjuvant chemotherapy $[1,8]$. In addition, at 5-year follow-up, basal-like tumors show a worse outcome than luminal B tumors, and at around 10-year followup, the survival curves of luminal $B$ tumors tend to cross those of basal-like tumors [8]. Thus, stratification of luminal $A$ and $B$ tumors, combined with tumor size and nodal status, allow us to predict resistance to endocrine therapy or to decide the length of endocrine treatment (5 years vs. 10 years) [8]. Numerous studies have reported that there are $30 \%$ to $44 \%$ discordance rates between the classifications based on gene expression predictors and surrogate classifications using IHC scoring of monoclonal antibody Ki-67 and PR status $[8,12]$. Distinguishing between luminal A-like and luminal B-like tumors using conventional pathology has proven impractical, as it might not provide a clinically useful threshold [6].

Within HR-positive/HER2-negative tumors, occurrence rates of the non-luminal subtypes (HER2-enriched and basal-like tumors) by gene expression profiling are as follows: the HER2-enriched type exists in $5.5 \%-11.0 \%$ and the basal-like type in 1\% to $5 \%$ of HR-positive/HER2-negative tumors [8]. The non-luminal subtypes of early breast cancers showed worse outcomes compared to the luminal A subtype when they were treated with 5 years of adjuvant tamoxifen-only [13]. This study suggests that tumors of the ERpositive but non-luminal subtype might not benefit from endocrine treatment. One study reported that $80 \%$ of ER-positive tumors with low expression (1\%-9\%) belonged to non-luminal subtypes [14].

The most influential contribution of microarray-based technology has been to the development of commercially available prognostic signatures, including the 70-gene MammaPrint microarray assay (Agendia, Amsterdam, The Netherlands), the 21-gene Oncotype DX assay (Genomic Health, Redwood City, CA, USA), and the 50-gene PAM50 assay (Prosigna, NanoString Technologies, Seattle, WA, USA) [1]. These signatures composed of different gene lists have been implemented to identify breast cancer patients with good or poor prognosis based on the expression levels of proliferation-associated genes [1]. All signatures show the highest discriminatory power for ER-positive tumors, but they have limited use for ER-negative tumors, since more than $95 \%$ of ER-negative tumors show high

Table 2. Treatment-oriented classification of subgroups of breast cancer from the St. Gallen Consensus 2015

\begin{tabular}{|c|c|c|c|}
\hline Clinical grouping & & Note & Type of therapy \\
\hline Triple-negative & & Negative ER, PR, and HER2 & $\begin{array}{l}\text { Cytotoxic chemotherapy including anthracycline } \\
\text { and taxane }\end{array}$ \\
\hline HR (-) and HER2 (+) & & ASCO/CAP guidelines ${ }^{a)}$ & $\begin{array}{l}\text { T1a node negative: no chemotherapy } \\
\text { T1b, c node negative: chemotherapy+trastuzumab } \\
\text { Higher T or N stage: anthracycline } \rightarrow \text { taxane with } \\
\text { trastuzumab }\end{array}$ \\
\hline HR $(+)$ and HER2 (+) & & ASCO/CAP guidelines ${ }^{\text {a) }}$ & As above+endocrine therapy \\
\hline HR $(+)$ and HER2 $(-)$ & & ER and/or PR $(+) \geq 1 \%^{\mathrm{b})}$ & \\
\hline Luminal A-like & $\begin{array}{l}\text { High receptor, } \\
\text { low proliferation, } \\
\text { low tumor burden }\end{array}$ & $\begin{array}{l}\text { Multiparameter molecular marker 'favorable } \\
\text { prognosis' if available } \\
\text { High ER/PR and clearly low Ki-67' } \\
\text { Low or absent nodal involvement (N 0-3), smaller T } \\
\text { size (T1,T2) }\end{array}$ & $\begin{array}{l}\text { Endocrine therapy alone according to menopausal } \\
\text { status }\end{array}$ \\
\hline Intermediate & & $\begin{array}{l}\text { Multiparameter molecular marker 'intermediate' } \\
\text { if available }{ }^{c} \\
\text { Uncertainty persists about degree of risk and } \\
\text { responsiveness to endocrine and cytotoxic therapies }\end{array}$ & - \\
\hline Luminal B-like & $\begin{array}{l}\text { Low receptor, } \\
\text { high proliferation, } \\
\text { high tumor burden }\end{array}$ & $\begin{array}{l}\text { Multiparameter molecular marker 'unfavorable } \\
\text { prognosis' if available; lower ER/PR with clearly } \\
\text { high Ki-67'; more extensive nodal involvement, } \\
\text { histological grade 3, extensive lymphovascular } \\
\text { invasion, larger T size (T3) }\end{array}$ & $\begin{array}{l}\text { Endocrine therapy+adjuvant cytotoxic } \\
\text { chemotherapy in many cases }\end{array}$ \\
\hline
\end{tabular}

Modified from Coates AS et al. Ann Oncol 2015;26:1533-1546 [6], according to the Creative Commons license.

ER, estrogen receptor; PR, progesterone receptor; HER2, human epidermal growth factor receptor 2; ASCO, American Society of Clinical Oncology; CAP, College of American Pathologists; IHC, immunohistochemistry.

${ }^{a}$ IHC of c-erbB-2 staining 3+ score was defined as HER2 positive, and the 0 or $1+$ score was negative. For tumors with 2+ score, HER-2 gene copies to the centromeric region of chromosome 17 ratios of 2.2 or more on fluorescence in situ hybridization was interpreted as amplified. ${ }^{\text {b)}}$ ER values between $1 \%$ and $9 \%$ were considered equivocal. Thus, endocrine therapy alone cannot be relied upon for patients with these values. ER (-), ER (+) (1\%-10\%) tumors were clinicopathologically more similar to ER (-) than ER (+) tumors, but they would be classified as ER (+). ${ }^{\mathrm{C}} \mathrm{Ki}-67$ scores should be interpreted in the light of local laboratory values: as an example, if a laboratory has a median Ki-67 score in receptor-positive disease of $20 \%$, values of $30 \%$ or above could be considered clearly high; those of $10 \%$ or less clearly low. 
Table 3. Imaging phenotypes according to the molecular subtypes

\begin{tabular}{|c|c|c|c|}
\hline Clinical grouping & Mammography & Ultrasonography & MRI \\
\hline Triple-negative & $\begin{array}{l}\text { A mass with a relatively } \\
\text { circumscribed margin without } \\
\text { calcifications }\end{array}$ & $\begin{array}{l}\text { A distinct mass with a circumscribed margin } \\
\text { and posterior acoustic enhancement }\end{array}$ & $\begin{array}{l}\text { A mass with rim enhancement and internal } \\
\text { high signal intensity on T2-weighted MRI } \\
\text { Presence of intratumoral necrosis and } \\
\text { irregular mass associated with nonresponse to } \\
\text { neoadjuvant chemotherapy } \\
\text { Peritumoral edema on T2-weighted MRI } \\
\text { associated with worse recurrence free survival }\end{array}$ \\
\hline HR $(-)$ and HER2 (+) & $\begin{array}{l}\text { Microcalcifications, branching } \\
\text { or fine linear calcifications } \\
\text { High suspicion for malignancy }\end{array}$ & $\begin{array}{l}\text { Irregular mass with a not-circumscribed } \\
\text { margin (circumscribed margin showing } \\
\text { decreased possibility of HER2 type) } \\
\text { High suspicion for malignancy }\end{array}$ & $\begin{array}{l}\text { A washout or fast initial kinetics } \\
\text { Multicentric and/or multifocal disease were } \\
\text { more frequently found in HER2 type or luminal } \\
\text { B type }\end{array}$ \\
\hline $\operatorname{HR}(+)$ and HER2 (-) & $\begin{array}{l}\text { A mass with a } \\
\text { poorlycircumscribed margin }\end{array}$ & $\begin{array}{l}\text { A mass with a poorly circumscribed margin } \\
\text { and posterior acoustic shadowing }\end{array}$ & - \\
\hline
\end{tabular}

MRI, magnetic resonance imaging; HR, hormone receptor; HER2, human epidermal growth factor receptor 2.

expression levels of proliferation-related genes $[1,15]$.

\section{HER2-Enriched Subtype}

Tumors with HER2 overexpression are found in $15 \%$ to $25 \%$ of invasive breast cancers and they show a worse prognosis but respond well to HER2-targeted therapies [16]. Heterogeneous intrinsic subtypes exist within HER2-positive tumors, which indicates the potential for predicting the degree of a patient's response to trastuzumab [6]. Within the HER2 subtype of breast cancer, HRpositive tumors were associated with increased disease-free survival and overall survival compared to HR-negative tumors-regardless of clinicopathologic factors-in the 4-year follow-up to the National Surgical Adjuvant Breast and Bowel Project B-31 trials [17]. In the first 5-year follow-up results from the National Comprehensive Cancer Network centers, more cancer recurrences were reported from the HR-negative tumor group than the HR-positive tumor group [14]. Women with HR-negative/HER2-positive tumors showed less first recurrence in bone and more recurrence in the brain [18].

In addition, women with HR-negative/HER2-positive tumors had a higher $p C R$ rate than those with HR-positive/HER2-positive tumors [19]. The $p C R$ rate could be increased to over $70 \%$ using a doubleHER2 blockade treatment either with trastuzumab plus lapatinib or trastuzumab plus pertuzumab in addition to an anthracycline/ taxane-based chemotherapy [6].

\section{Imaging Phenotype of Breast Cancer Subtypes}

A number of studies regarding imaging features according to the molecular subtypes have been published during the last 15 years. As commercially available microarray-based genetic analysis has been increasingly used, the definition of molecular subtype in the earlier imaging studies has changed from the alternate classification using IHC [20-29] to the intrinsic subtype classification using gene expression profiling techniques [30]. In addition, imaging parameters have changed from the Breast Imaging Reporting and Data System lexicon $[20,24,26-29]$ to the quantitative parameters derived from texture analysis using computer-aided analysis software [30]. The primary outcome has also changed from distinguishing each subtype [20-29] to identifying an association between imaging parameters with response to a treatment $[31,32]$ or recurrence-free survival outcomes [32].

Imaging phenotypes according to the molecular subtypes are summarized in Table 3. TNBC tends to present as a mass with a relatively circumscribed margin, without calcifications (Fig. 1A) [20]. Absence of associated calcifications and lower associated ductal carcinoma in situ suggest rapid progression of malignant transformation, bypassing the stage of in situ [20]. On ultrasonography (US), a distinct mass with a circumscribed margin and posterior acoustic enhancement is frequently reported in TNBC (Fig. 1B). TNBC showed greater stiffness than ER-positive tumors in one study [21], although such stiffness was not consistently found in other studies $[22,23]$. On magnetic resonance imaging (MRI), a mass with rim enhancement (Fig. 1C) and internal high signal intensity on T2-weighted magnetic resonance (MR) image (Fig. 1D) was frequently reported in TNBC [24-26]. For the prediction of response to a treatment or the survival outcome of TNBC, presence of intratumoral necrosis and irregular mass on MRI were reported to be associated with nonresponse to neoadjuvant chemotherapy [31] and peritumoral edema on T2-weighted MR image has also been reported to be associated with worse recurrence-free survival [32].

With regard to the HR-positive tumor, a poorly circumscribed 


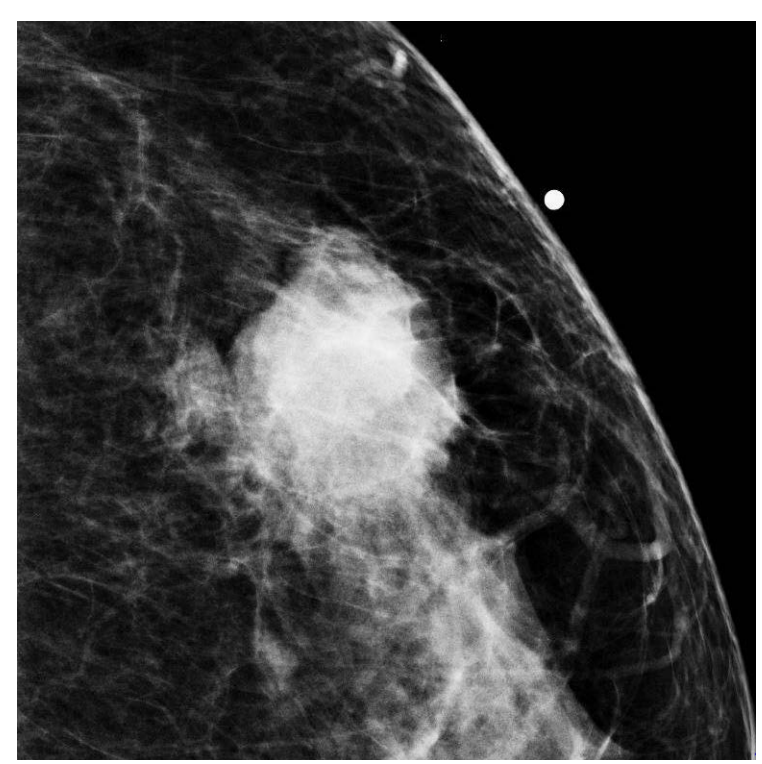

A

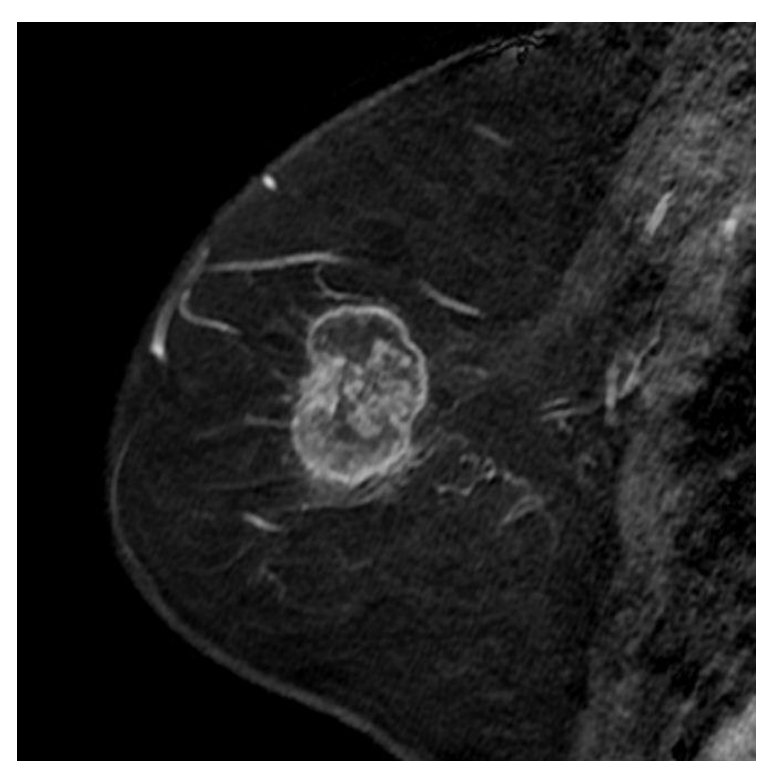

C

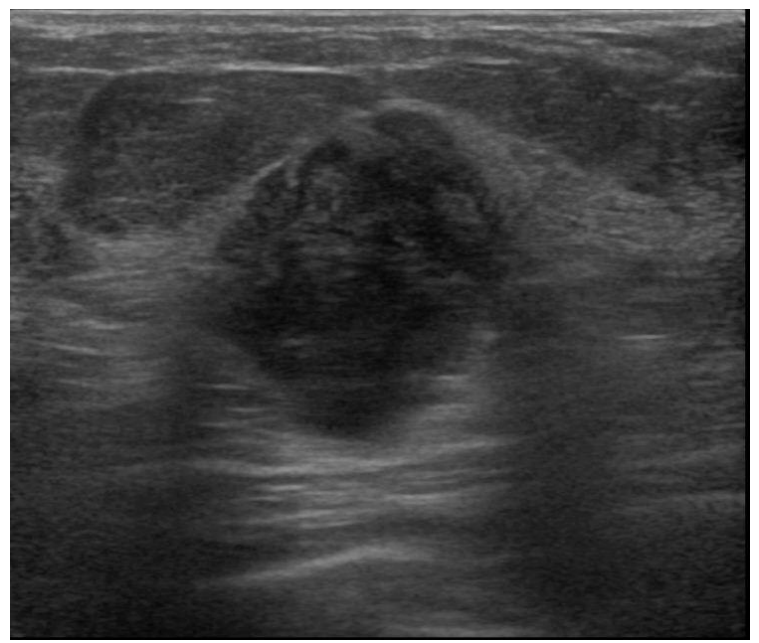

B

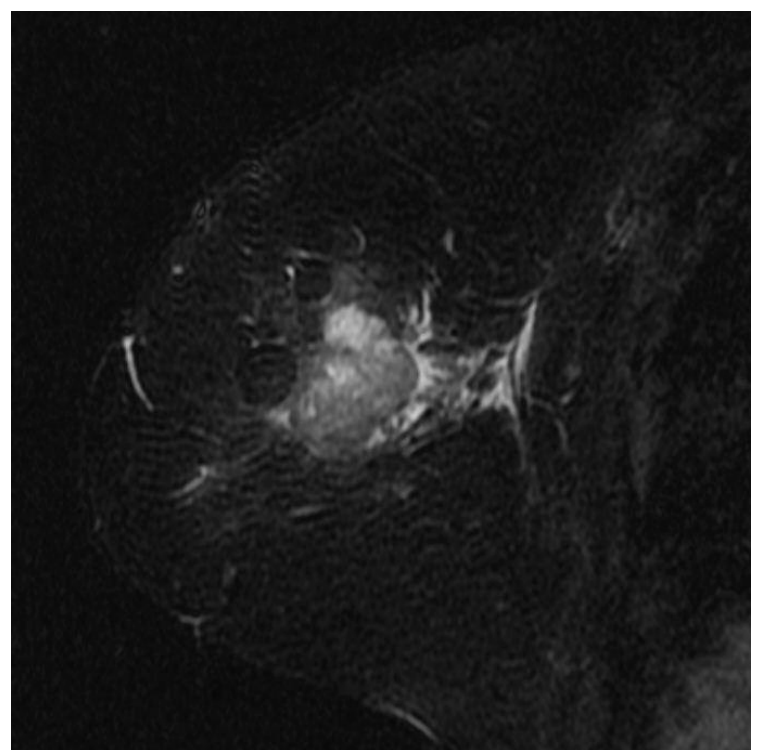

D

Fig. 1. A 59-year-old woman with a basal-like breast cancer.

A. Mammography shows an irregular mass with an indistinct margin without calcifications. B. Sonograms shows an irregular mass with a circumscribed margin and a posterior acoustic enhancement. C. Gadolinium-enhanced T1-weighted magnetic resonance (MR) image shows an irregular mass with rim-enhancement. D. T2-weighted MR image shows an irregular mass with internal high signal intensity. Histopathology revealed an invasive ductal carcinoma with high histologic grade. Immunohistochemistry analysis showed estrogen receptor -negative, progesterone receptor-negative, human epidermal growth factor receptor 2-negative, cytokeratin 5/6-positive, and Ki-67-30\% positive.

margin, and posterior acoustic shadowing were associated with HR-positive tumors and lower-grade tumors (Fig. 2A, B), whereas a posterior enhancement and a circumscribed margin were associated with HR-negative or higher-grade tumors [29-31]. Recently, a study using the TCGA Imaging Archive reported that a higher enhancement ratio of lesion to background parenchyma on MRI was associated with the luminal B subtype [30].

According to a meta-analysis of the imaging features of tumors with HER2 overexpression, several imaging features were associated with HER2 overexpression, as follows: presence of 


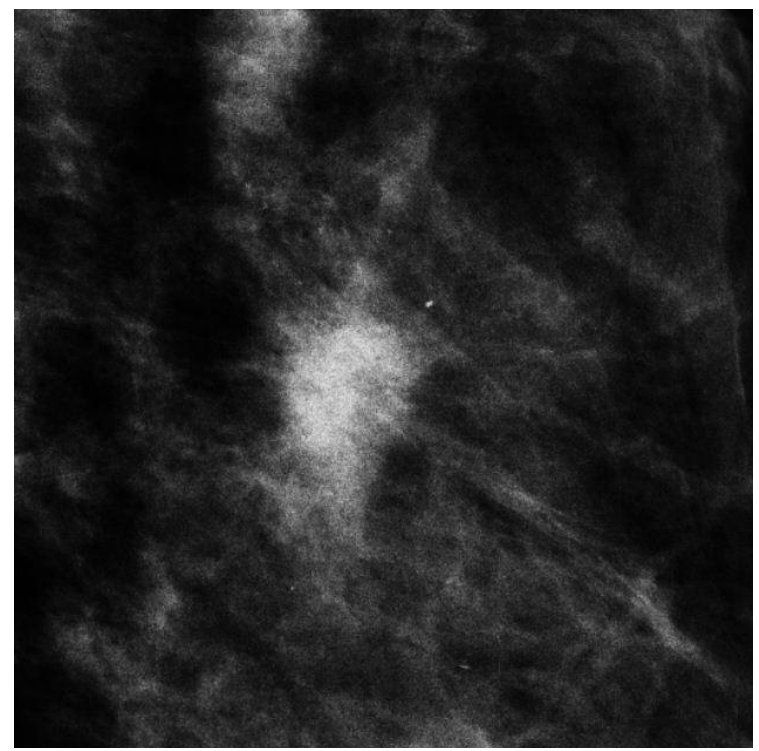

A

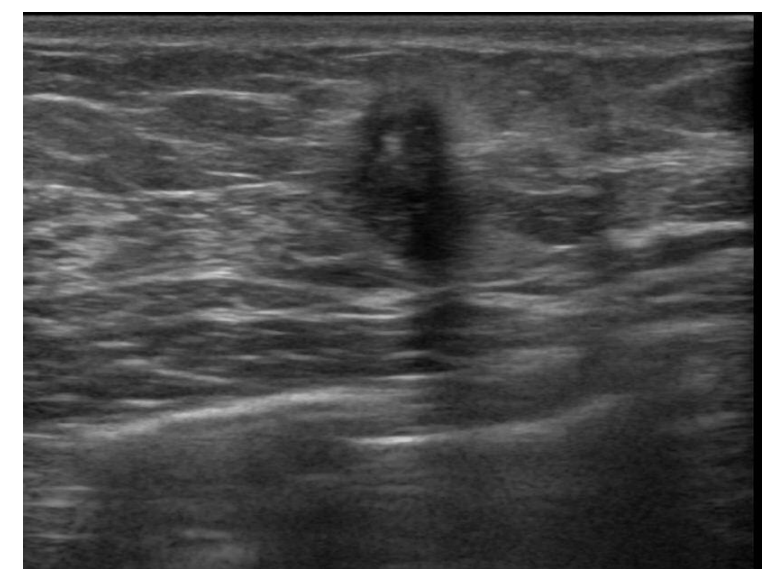

B

Fig. 2. A 45-year-old woman with a luminal A-like breast cancer.

A. Mammography shows a spiculated mass with calcifications. B. Sonogram shows an irregular mass with spiculated margin and posterior acoustic shadowing. Histopathology revealed an invasive ductal carcinoma with low histologic grade. Immunohistochemistry analysis showed estrogen receptor-85\% positive, progesterone receptor-90\% positive, and human epidermal growth factor receptor 2 -negative.

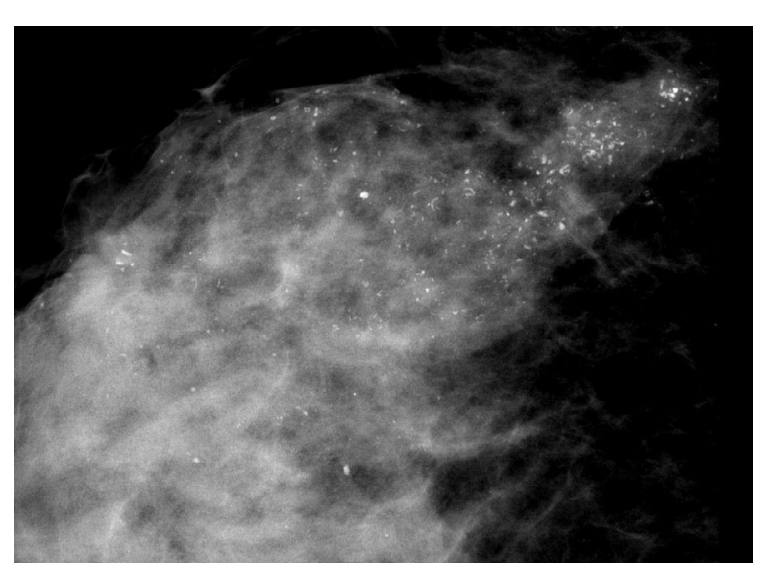

A

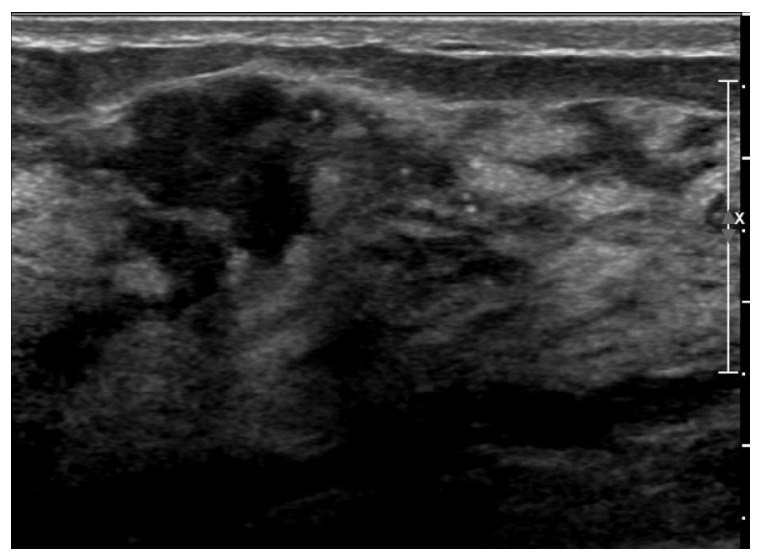

B

Fig. 3. A 35-year-old woman with a human epidermal growth factor receptor 2 (HER2)-positive breast cancer.

A. Mammography shows segmental, pleomorphic, linear branching microcalcifications. B. Songogram shows an ill-defined, irregular mass with calcifications within surrounding ductal changes. Histopathology revealed an invasive ductal carcinoma with high histologic grade. Immunohistochemistry analysis showed estrogen receptor-negative and progesterone receptor-negative. HER2 was positive on fluorescence in situ hybridization.

microcalcifications, branching or fine linear calcifications, extremely dense breasts, high suspicion for malignancy on mammography or US, irregularly shaped masses on US (Fig. 3A, B) and a washout or fast initial kinetics on MRI [33]. A circumscribed margin showed a decreased probability of HER2 overexpression. Another study reported that multicentric and/or multifocal disease was more frequently found in the HER2 subtype or luminal B subtype than luminal A or basal-like subtype [34].

In addition, the multigene assays of MammaPrint, Oncotype DX, or PAM50 for predicting cancer recurrences have been used to evaluate associations between imaging phenotypes and recurrence scores [35-38]. Texture parameters on postcontrast MRI, vascularity or acoustic posterior enhancement on US, or pleomorphic microcalcifications on mammography were reported to be significant 
radiomic signatures related to high recurrence scores [35-38].

\section{The Role of Radiologists in Precision Medicine}

Precision medicine is defined as tailoring medical treatment according to individual patients and their tumor characteristics [39]. Staging, grading, and classification of subtypes allow patients to be categorized into subpopulations that may benefit from a targeted treatment. Radiologists can play an important role in precision medicine, as follows. First, US and MR images are accurate in the quantification of the residual tumor burden and in determining response to systemic treatment. Second, they have advantages in repeated evaluation and depiction of the whole tumor, threedimensionally [39], in contrast to percutaneous tissue sampling, which is not representative of the whole tumor, and repeated sequencings based on gene expression profiling, which are not always available. Finally, sophisticated texture analysis using imaging parameters including vascularity or stiffness would help physicians depict disease heterogeneity and identify mutations during treatment.

\section{Conclusion}

As breast cancer is a heterogeneous disease and evolves continuously following systemic treatment, refined knowledge of imaging phenotypes according to molecular subtypes could be helpful in realizing the goals of precision medicine.

ORCID: Nariya Cho: http://orcid.org/0000-0003-4290-2777

\section{Conflict of Interest}

No potential conflict of interest relevant to this article was reported.

\section{References}

1. Ng CK, Schultheis AM, Bidard FC, Weigelt B, Reis-Filho JS. Breast cancer genomics from microarrays to massively parallel sequencing: paradigms and new insights. J Natl Cancer Inst 2015;107:djv015.

2. Cancer Genome Atlas Network. Comprehensive molecular portraits of human breast tumours. Nature 2012;490:61-70.

3. Sorlie T, Perou CM, Tibshirani R, Aas T, Geisler S, Johnsen H, et al. Gene expression patterns of breast carcinomas distinguish tumor subclasses with clinical implications. Proc Natl Acad Sci U S A 2001;98:10869-10874.

4. Parker JS, Mullins M, Cheang MC, Leung S, Voduc D, Vickery T, et al. Supervised risk predictor of breast cancer based on intrinsic subtypes. J Clin Oncol 2009;27:1160-1167.
5. Goldhirsch A, Winer EP, Coates AS, Gelber RD, Piccart-Gebhart M, Thurlimann $B$, et al. Personalizing the treatment of women with early breast cancer: highlights of the St Gallen International Expert Consensus on the Primary Therapy of Early Breast Cancer 2013. Ann Oncol 2013;24:2206-2223.

6. Coates AS, Winer EP, Goldhirsch A, Gelber RD, Gnant M, PiccartGebhart M, et al. Tailoring therapies: improving the management of early breast cancer: St Gallen International Expert Consensus on the Primary Therapy of Early Breast Cancer 2015. Ann Oncol 2015;26:1533-1546.

7. Polyak K. Breast cancer: origins and evolution. J Clin Invest 2007;117:3155-3163.

8. Prat A, Pineda E, Adamo B, Galvan P, Fernandez A, Gaba L, et al. Clinical implications of the intrinsic molecular subtypes of breast cancer. Breast 2015;24 Suppl 2:S26-S35.

9. Prat A, Adamo B, Cheang MC, Anders CK, Carey LA, Perou CM. Molecular characterization of basal-like and non-basal-like triplenegative breast cancer. Oncologist 2013;18:123-133.

10. Lehmann BD, Bauer JA, Chen $X$, Sanders ME, Chakravarthy $A B$, Shyr $Y$, et al. Identification of human triple-negative breast cancer subtypes and preclinical models for selection of targeted therapies. J Clin Invest 2011;121:2750-2767.

11. Liedtke C, Mazouni C, Hess KR, Andre F, Tordai A, Mejia JA, et al. Response to neoadjuvant therapy and long-term survival in patients with triple-negative breast cancer. J Clin Oncol 2008;26:12751281.

12. Chia SK, Bramwell VH, Tu D, Shepherd LE, Jiang S, Vickery T, et al. A 50-gene intrinsic subtype classifier for prognosis and prediction of benefit from adjuvant tamoxifen. Clin Cancer Res 2012;18:44654472.

13. Prat A, Parker JS, Fan C, Cheang MC, Miller LD, Bergh J, et al. Concordance among gene expression-based predictors for ERpositive breast cancer treated with adjuvant tamoxifen. Ann Oncol 2012;23:2866-2873.

14. Iwamoto T, Booser D, Valero V, Murray JL, Koenig K, Esteva $\mathrm{FJ}$, et al. Estrogen receptor (ER) mRNA and ER-related gene expression in breast cancers that are $1 \%$ to $10 \%$ ER-positive by immunohistochemistry. J Clin Oncol 2012;30:729-734.

15. Reis-Filho JS, Pusztai L. Gene expression profiling in breast cancer: classification, prognostication, and prediction. Lancet 2011;378:1812-1823.

16. Arteaga CL, Sliwkowski MX, Osborne CK, Perez EA, Puglisi F, Gianni L. Treatment of HER2-positive breast cancer: current status and future perspectives. Nat Rev Clin Oncol 2012;9:16-32.

17. Perez EA, Romond EH, Suman VJ, Jeong JH, Davidson NE, Geyer CE Jr, et al. Four-year follow-up of trastuzumab plus adjuvant chemotherapy for operable human epidermal growth factor receptor 2-positive breast cancer: joint analysis of data from NCCTG N9831 and NSABP B-31. J Clin Oncol 2011;29:3366-3373. 
18. Vaz-Luis I, Ottesen RA, Hughes ME, Marcom PK, Moy B, Rugo $\mathrm{HS}$, et al. Impact of hormone receptor status on patterns of recurrence and clinical outcomes among patients with human epidermal growth factor-2-positive breast cancer in the National Comprehensive Cancer Network: a prospective cohort study. Breast Cancer Res 2012;14:R129.

19. Gianni L, Eiermann W, Semiglazov V, Lluch A, Tjulandin S, Zambetti $M$, et al. Neoadjuvant and adjuvant trastuzumab in patients with HER2-positive locally advanced breast cancer (NOAH): follow-up of a randomised controlled superiority trial with a parallel HER2negative cohort. Lancet Oncol 2014;15:640-647.

20. Dogan BE, Turnbull LW. Imaging of triple-negative breast cancer. Ann Oncol 2012;23 Suppl 6:vi23-vi29.

21. Chang JM, Park IA, Lee SH, Kim WH, Bae MS, Koo HR, et al. Stiffness of tumours measured by shear-wave elastography correlated with subtypes of breast cancer. Eur Radiol 2013;23:2450-2458.

22. Youk JH, Gweon HM, Son EJ, Kim JA, Jeong J. Shear-wave elastography of invasive breast cancer: correlation between quantitative mean elasticity value and immunohistochemical profile. Breast Cancer Res Treat 2013;138:119-126.

23. Ganau S, Andreu FJ, Escribano F, Martin A, Tortajada L, Villajos M, et al. Shear-wave elastography and immunohistochemical profiles in invasive breast cancer: evaluation of maximum and mean elasticity values. Eur J Radiol 2015;84:617-622.

24. Luck AA, Evans AJ, James JJ, Rakha EA, Paish EC, Green AR, et al. Breast carcinoma with basal phenotype: mammographic findings. AJR Am J Roentgenol 2008;191:346-351.

25. Uematsu T, Kasami M, Yuen S. Triple-negative breast cancer: correlation between MR imaging and pathologic findings. Radiology 2009;250:638-647.

26. Youk JH, Son EJ, Chung J, Kim JA, Kim EK. Triple-negative invasive breast cancer on dynamic contrast-enhanced and diffusionweighted MR imaging: comparison with other breast cancer subtypes. Eur Radiol 2012;22:1724-1734.

27. Irshad A, Leddy R, Pisano E, Baker N, Lewis M, Ackerman S, et al. Assessing the role of ultrasound in predicting the biological behavior of breast cancer. AJR Am J Roentgenol 2013;200:284290.

28. Aho $M$, Irshad A, Ackerman SJ, Lewis $M$, Leddy R, Pope $T L$, et al. Correlation of sonographic features of invasive ductal mammary carcinoma with age, tumor grade, and hormone-receptor status. J Clin Ultrasound 2013;41:10-17.

29. Shin HJ, Kim HH, Huh MO, Kim MJ, Yi A, Kim H, et al. Correlation between mammographic and sonographic findings and prognostic factors in patients with node-negative invasive breast cancer. $\mathrm{Br} J$ Radiol 2011;84:19-30.

30. Mazurowski MA, Zhang J, Grimm LJ, Yoon SC, Silber JI. Radiogenomic analysis of breast cancer: luminal $B$ molecular subtype is associated with enhancement dynamics at MR imaging. Radiology 2014;273:365-372.

31. Kawashima H, Inokuchi M, Furukawa H, Kitamura S. Triplenegative breast cancer: are the imaging findings different between responders and nonresponders to neoadjuvant chemotherapy? Acad Radiol 2011;18:963-969.

32. Bae MS, Shin SU, Ryu HS, Han W, Im SA, Park IA, et al. Pretreatment MR imaging features of triple-negative breast cancer: association with response to neoadjuvant chemotherapy and recurrence-free survival. Radiology 2016 May 19 [Epub]. http://dx.doi.org/10.1148/ radiol.2016152331.

33. Elias SG, Adams A, Wisner DJ, Esserman LJ, van't Veer LJ, Mali WP, et al. Imaging features of HER2 overexpression in breast cancer: a systematic review and meta-analysis. Cancer Epidemiol Biomarkers Prev 2014;23:1464-1483.

34. Grimm LJ, Johnson KS, Marcom PK, Baker JA, Soo MS. Can breast cancer molecular subtype help to select patients for preoperative MR imaging? Radiology 2015;274:352-358.

35. Li H, Zhu Y, Burnside ES, Drukker K, Hoadley KA, Fan C, et al. MR imaging radiomics signatures for predicting the risk of breast cancer recurrence as given by research versions of MammaPrint, Oncotype DX, and PAM50 gene assays. Radiology 2016 May 5 [Epub]. http://dx.doi.org/10.1148/radiol.2016152110.

36. Dialani V, Gaur S, Mehta TS, Venkataraman S, Fein-Zachary V, Phillips J, et al. Prediction of low versus high recurrence scores in estrogen receptor-positive, lymph node-negative invasive breast cancer on the basis of radiologic-pathologic features: comparison with Oncotype DX test recurrence scores. Radiology 2016;280:370378.

37. Sutton EJ, Oh JH, Dashevsky BZ, Veeraraghavan $H$, Apte AP, Thakur $\mathrm{SB}$, et al. Breast cancer subtype intertumor heterogeneity: MRIbased features predict results of a genomic assay. J Magn Reson Imaging 2015;42:1398-1406.

38. Yepes MM, Romilly AP, Collado-Mesa F, Net JM, Kiszonas R, Arheart $\mathrm{KL}$, et al. Can mammographic and sonographic imaging features predict the Oncotype DX recurrence score in T1 and T2, hormone receptor positive, HER2 negative and axillary lymph node negative breast cancers? Breast Cancer Res Treat 2014;148:117-123.

39. Thrall JH. Moreton lecture: imaging in the age of precision medicine. J Am Coll Radiol 2015;12:1106-1111. 